\title{
Intensitas Penggunaan Media Sosial Instagram dengan Gaya Hidup Hedonis Pada Remaja
}

\author{
Sri Wahyuningsih", Ardian Adi Putra ${ }^{2}$ \\ Fakultas Psikologi Universitas Abdurrab Pekanbaru \\ Ayusriwahyuningsih03@gmail.com¹,Ardian.adi.putra@gmail.com²
}

\begin{abstract}
Penelitian ini bertujuan untuk mengetahui hubungan antara intensitas penggunaan media sosial instagram dengan gaya hidup hedonis pada remaja di Pekanbaru. Subjek dalam penelitian ini sebanyak 300 (125 laki-laki dan 175 perempuan) orang dengan usia 12-24 tahun. Penelitian ini menggunakan teknik accidental sampling serta menggunakan dua skala psikologi yaitu skala intensitas penggunaan media sosial instagram dan skala gaya hidup hedonis. Pengujian hipotesis menggunaan analisis korelasi Pearson Product Moment. Hasil koefisien korelasi menghasilkan $\mathrm{r}=0,844$ dengan taraf signifikansi $p=0,000(p<0,05)$ menunjukkan bahwa ada hubungan antara intensitas penggunaan media sosial instagram dengan gaya hidup hedonis pada remaja di Pekanbaru. Intensitas penggunaan media sosial instagram yang tinggi akan meningkatkan gaya hidup hedonis pada remaja, begitu pula sebaliknya. Secara keseluruhan, hasil penelitian menunjukkan remaja di Pekanbaru memiliki intensitas penggunaan media sosial instagram dan gaya hidup hedonis yang tergolong sedang.
\end{abstract}

Kata Kunci : intensitas penggunaan, media social insatgram, gaya hidup hedonis, remaja

This study aims to determine the relationship between the intensity of the use of Instagram social media with the hedonism lifestyle of adolescents in Pekanbaru. Subjects in this study were 300 adolescents (125 men and 175 women) aged 12-24 years. This research uses the accidental sampling technique and uses two psychological scales namely the intensity scale of the use of Instagram social media and the hedonism lifestyle scale. Hypothesis testing uses the Pearson Product Moment correlation analysis. The results of the correlation coefficient with $r=0.844$ with a significance level of $\mathrm{p}=0,000(\mathrm{p}<0.05)$ indicating that there is a relationship between the intensity of the use of Instagram social media with a hedonism lifestyle in adolescents in Pekanbaru. The high intensity of using social media on Instagram will improve the hedonism lifestyle of adolescents and vice versa. Overall, the results of the study show that adolescents in Pekanbaru have the intensity of using social media on Instagram and the hedonism lifestyle that is classified as moderate.

Keywords: hedonism lifestyle, adolescents

\section{PENDAHULUAN}

Gaya hidup hedonis dianggap sebagai pola hidup yang berlandaskan pada aktivitas atau kegiatan yang berfokus pada kesenangan, seperti senang bermain atau menghabiskan watku di luar rumah, memberi barang mahal, maupun menjadi pusat perhatian (Kotler \& Amstrong, 2007). Perilaku hedonis ini tergambar pada remaja saat ini, remaja cenderung menghindari percakapan hedonis serta lebih menyukai pembicaraan terkait masalah fashion, film terbaru maupun bentuk perilaku hedonis lainnya (Praja \& Damayantie, 2013).

Setiap individu memiliki gaya hidup yang berbeda, menurut Kotler d Amstrong (2007) gaya hidup individu akan menunjukkan pola kehidupan pribadi individu di masyarakat, tergambar dari perilaku di depan umum serta lambang-lambang sosial. Gaya hidup hedonis akan terlihat pada pola kehidupan dan perilaku mewah seseorang untuk menunjukkan kelas sosial ekonominya dan mencari kesenangan agar dapat diterima di lingkungannya.

Agustina (2016) dalam penelitiannya mengungkapkan bahwa beberapa dampak dari gaya hidup hedonisme adalah adanya pola hidup yang berorientasi materialism serta pola pikir pragmatis, bahkan pada pelajar bisa menyebabkan menurunnya motivasi dan prestasi belajar. 
Beberapa penelitian menunjukkan bahwa individu, khususnya pelajar di Pekanbaru menunjukkan pola perilaku hedonis dengan aktivitas clubbing, berpergian ketempat hiburan (Febrianti, 2017; Ifwar, 2017), perilaku konsumtif dengan pembelian barang barang mahal (Febrianti, 2017; Khoirunnas, 2017). Penyebab gaya hidup hedonis dikalangan remaja saat ini yaitu pergaulan teman sebaya, kurangnya kontrol dari orang tua yang selalu mewujudkan keinganan anaknya serta media sosial yang sedang berkembang.

Berdasarkan data (Hootsuite (we are social), 2019) total pengguna aktif media sosial di Indonesia berjumlah 150 Juta, sedang menurut (APJII [Asosiasi Penyedia Jasa Internet Indonesia], 2019) mencapai 171,17 juta jiwa dengan pengguna terbanyak pada usia 12-24 tahun. Instagram merupakan media sosial kedua yang sering di kunjungi oleh pengguna internet setelah facebook (APJII, 2019; Hootsuite (we are social), 2019) dengan 62 juta di antaranya adalah pengguna instagram dengan kisaran usia tertinggi di rentangan 18-34 tahun (APJII, 2019). Dengan kata lain instagram merupakan sebuah aplikasi yang banyak digunakan oleh kaum muda pada saat ini. Media sosial instagram pada umumnya banyak digunakan oleh kaum muda Indonesia, karena memiliki berbagai macam fitur menarik, seperti boomerang, layout, hypogram, youcam. Sehingga sudah menjadi kegiatan sehari-hari kaum muda dalam melakukan komunikasi secara tidak langsung dengan menggunakan media sosial instagram.

Saat ini penggunaan instagram sudah dianggap sebagai bagian dari gaya hidup (Irawan, 2017). Beberapa penelitian juga menemukan korelasi antara penggunaan sosial media serta intensitasnya dengan gaya hidup, khususnya gaya hidup hedonism (Mufidah \& Wulansari, 2018; Prasetyo, 2019). Berdasarkan uraian di atas terkait perilaku hedonis dan penggunaan media sosial instagram pada remaja semakin banyak terjadi dimana-dimana, maka disini peneliti ingin mengetahui apakah ada hubungan intensitas penggunaan media sosial instagram terhadap gaya hidup hedonis remaja di Kota Pekanbaru.

\section{METODE}

Subjek dalam penelitian ini berjumlah 300 orang. Merupakan remaja Pekanbaru dengan usia 14-24 tahun. Sekitar 125 subjek berjenis kelamin laki-laki sedang 175 lainnya adalah remaja perempuan. Sampel diambil dengan menggunakan accidental sampling. Dalam penelitian ini ada dua alat ukur yang digunakan.Pertama, skala intensitas penggunaan media sosial instagram yang berjumlah 20 aitem dan reliabilitas Alpha Cronbach $(\alpha), 0,923$ dan daya diskriminasi aitem berkisar 0,263-0,777. Kedua, skala gaya hidup hedonis memiliki koefisien reliabilitas Alpha Cronbach $(\alpha)$ sebesar 0,928 dengan jumlah aitem 22 pernyataan, sedang daya diskriminasi aitem berkisaar dari 0,287-0,815. Penelitian ini menggunakan prinsip dari skala likert yang terdiri dari 5 kategori jawaban, yaitu "sangat tidak sesuai", "tidak sesuai", "Netral", "Sesuai", "Sangat Sesuai"

\section{HASIL}

Dalam penelitian ini berdasarkan tabel 1. diatas subjek laki-laki berjumlah 125 orang $(41,7 \%)$ sementara 58,3 \% lainnya atau setara 175 orang adalah perempuan. Mayoritas subjek memiliki kriteria usia 18-21 tahun (50,3\%) dengan jumlah 151 orang. Melalui data juga di ketahui bahwa durasi penggunaan Instagram tertinggi berdasarkan satuan jam adalah 1-2 jam dengan $25,7 \%$ subjek. Jumlah ini berbeda tipis dengan jumlah durasi pengguna instagram 3-4 jam dengan $25 \%$ subjek. Sementara rata-rata harian subjek dalam menggunakan media 
Instagrama adalah 2-3 kali sehari dengan persentase $24,7 \%$.

Tabel 1.

Deskripsi demografi subjek penelitian

\begin{tabular}{llcr}
\hline Kriteria & Deskripsi & Frekuensi & Persentase \\
\hline Jenis Kelamin & Laki-laki & 125 & $41,7 \%$ \\
Usia & Perempuan & 175 & $58,3 \%$ \\
& $14-17$ tahun & 108 & $36 \%$ \\
Durasi Penggunaan Ig per Jam & $18-21$ tahun & 151 & $50,3 \%$ \\
& $22-24$ tahun & 41 & $13,7 \%$ \\
& $<$ dari 1 jam & 65 & $21,7 \%$ \\
& $1-2$ jam & 77 & $25,7 \%$ \\
& $3-4$ jam & 75 & $25 \%$ \\
Durasi Penggunaan Ig Perhari & $5-6$ jam & 53 & $17,7 \%$ \\
& $>$ dari 6 jam & 30 & $10 \%$ \\
& Hanya 1 sehari & 19 & $6,3 \%$ \\
& $2-3$ kali sehari & 74 & $24,7 \%$ \\
& $4-5$ kali sehari & 63 & $21,0 \%$ \\
& $5-6$ kali sehari & 41 & $13,7 \%$ \\
& $>$ dari 6 kali sehari & 103 & $34,3 \%$ \\
\hline
\end{tabular}

Tabel 2.

Deskriptif statistik

\begin{tabular}{ccccccccc}
\hline \multirow{2}{*}{$\begin{array}{c}\text { Variabel } \\
\text { Intensitas penggunaan media } \\
\begin{array}{c}\text { sosial instagram } \\
\text { Gaya Hidup Hedonis }\end{array}\end{array}$} & Maks & Min & Mean & SD & Maks & Min & Mean & SD \\
\cline { 2 - 9 } & 99 & 29 & 68,5 & 16,0 & 100 & 20 & 60 & 13,3 \\
\hline
\end{tabular}

Berdasarkan tabel 2 dapat diketahui jumlah skor rata-rata (mean : 68,5, SD : 16,0) empirik lebih besar dari pada jumlah skor rata-rata (mean : 60, SD : 13,3) hipotetik pada skala intensitas penggunaan media sosial instagram $(68,5>60)$, hal ini menunjukkan bahwa intensitas penggunaan media sosial instagram pada remaja di Pekanbaru yang diteliti tinggi. Sementara jumlah skor rata-rata (mean : 69,6, SD : 19,9) empirik lebih besar dari pada jumlah skor ratarata (mean : 66, SD : 14,6) hipotetik pada skala gaya hidup hedonis $(69,6>66)$, hal ini menunjukkan bahwa gaya hidup hedonis pada remaja di Pekanbaru yang diteliti tinggi.

\section{Uji Asumsi}

Hasil uji normalitas dari variabel intensitas penggunaan media sosial instagram dengan gaya hidup hedonis pada remaja di Pekanbaru diperoleh, nilai $p$ sebesar 0,483 ( $p>0,05)$, dengan demikian data pada penelitian ini dapat berdistribusi normal. Hasil uji linearitas diperoleh bahwa $\mathrm{F}=13,799$ dan $p=0,000(<0,05)$. Dengan nilai signifikansi kurang dari 0,05, maka data pada penelitian ini dapat dikatakan linear. 


\section{Uji Hipotesis}

Hasil penelitian menggunakan teknik koefisien korelasi product moment pearson menunjukkan angka probabilitas $(\mathrm{p})=0,000(\mathrm{p}<0,05)$, maka dapat disimpulkan bahwa ada hubungan yang signifikan antara intensitas penggunaan media sosial instagram dengan gaya hidup hedonis pada remaja di Pekanbaru. Sementara itu, nilai $(r)=0,844$ yang artinya memiliki tingkat hubungan yang kuat antara kedua variabel dan memiliki arah hubungan yang positif, yaitu semakin tinggi intensitas penggunaan media sosial instagram maka semakin tinggi pula gaya hidup hedonis pada remaja. Dengan demikian hipotesis yang diajukan pada penelitian ini diterima. Nilai R square dalam penelitian ini sebesar 0,713 yang artinya sumbangan efektif intensitas penggunaan media sosial instagram terhadap gaya hidup hedonis pada remaja sebesar $7,13 \%$.

\section{PEMBAHASAN}

Penelitian ini bertujuan untuk mengetahui hubungan antara intensitas penggunaan media sosial instagram terhadap gaya hidup hedonis pada remaja. Hasil dari penelitian ini menunjukkan bahwa intensitas penggunaan media sosial instagram dan gaya hidup hedonis memiliki hubungan yang positif, artinya semikin tinggi intensitas penggunaan media sosial instagram, maka semakin tinggi pula gaya hidup hedonis pada remaja. Hal ini sesuai dengan penelitian sebelumnya yang mengungkapkan bahwa intensitas serta penggunaan sosial media memiliki hubungan dengna gaya hidup hedonisme (Martini, Octavianty, \& Harsono, 2015; Mufidah \& Wulansari, 2018; Prasetyo, 2019).

Pada awalnya remaja akan melakukan pengamatan melalui media sosial terkait perilaku, sikap maupun gaya hidup, semakin tinggi intensitas pengamatan yang dilakukan memberi peluang besar untuk meniru apa yang di amati. Melalui proses inilah kemudian gaya hidup yang tergambar dari pengamatan individu melalui Instagram dapat terinternalisasi. Hal ini sesuai dengan konsep modelling dari Albelrt Bandura. Teori modelling ini di dasarkan pada konsep teori belajar sosial, yang menggambarkan proses belajar di mulai melalui observasi, kemudian imitasi atau peniruan dan terakhir pemodelan (Alwisol, 2009). Proses belajar sosial ini dapat terjadi karena remaja cenderung menyerap semua informasi di media sosial, baik seperti cara bersikap, gaya hidup, dan perilaku lainnya yang itu semua dapat menarik perhatian dari orang lain agar dapat diterima di lingkungan mereka (Monks, Knoers, \& Haditono, 2004).

Penelitian terdahulu mengenai intensitas penggunaan instagram diteliti oleh Juwita, Budimansyah, dan Nurbayani (2015) yang menunjukkan hasil bahwa dampak negatif dari penggunaan media sosial instagram adalah munculnya sifat konsumtif serta menginginkan segala sesuatu didapatkan secara instan. Sifat konsumtif, jiwa juang sangat tipis serta keinginan sesuatu didapatkan secara instan adalah termasuk kedalam aspek-aspek gaya hidup hedonis (Kotler \& Amstrong, 2007). Penelitian dari Sakti dan Yulianto (2018) memberikan kesimpulan bahwa remaja yang menggunakan instagram secara aktif, akan melakukan tindakan mengkontruksi diri mereka berdasarkan pada persepsi orang-orang di sekitar mereka dalam memandang dirinya. Bahkan secara khusus penggunaan instagram dihubungkan dengan gaya hidup hedonism individu dengan akun instagram yang di ikuti (Utari, 2017).

Dalam penelitian ini gambaran intensitas penggunaan instagram dilihat dari durasi penggunaan instagram yang berkisar 2-3 jam, hal ini semakin memberikan kontribusi 
internalisasi gaya hidup dari pengamatan media oleh remaja. Temuan ini sebenarnya hampir sama dengan Syamsoedin, Bidjuni, dan Wowiling (2015) dalam penelitiannya menemukan bahwa durasi rata-rata penggunaan media sosial adalah 3-4 sehari. Hal ini hampir sama dengan data We Are Social (2019) yang menyatakan bahwa durasi pengunaan media sosial di Indonesia rata-rata berkisar 3 jam 26 menit.

\section{KESIMPULAN}

Instagram saat ini merupakan platform sosial media yang sangat di minati remaja. Intensitas penggunaannya semakin meningkat dari tahun ke tahun. Rata-rata penggunaan media sosial Instagram yang di habiskan remaja berdasarkan temuan ini adalah 2-3, bahkan 4 jam sehari. Durasi penggunaan instagram yang tinggi akan berdampak pada internalisasi aktivitas yang sering dilihat di media sosial, mulai dari perilaku sampai kepada gaya hidup. Hal ini di dasarkan pada konsep pemodelan, bahwa individu memiliki kemampuan untuk melakukan pengamatan pada satu perilaku, mengimitasi dan kemudian mengaplikasikannya dalam bentuk perilaku yang sama atau hampir sama, dan secara terus menerus menjadi gaya hidup. Dengan kata lain hal ini sesuai dengan hasil penelitian ini yang menunjukkan ada hubungan yang positif dan signifikan antara intensitas penggunaan media sosial instagram dengan gaya hidup hedonis. semakin tinggi intensitas penggunaan media sosial instagram maka semakin tinggi gaya hidup hedonis, sebaliknya semakin rendah intensitas penggunaan media sosial instagram maka semakin rendah gaya hidup hedonis pada remaja di Pekanbaru.

\section{DAFTAR PUSTAKA}

Alwisol. (2009). Psikologi Kepribadian. Yogyakarta: UMM Press.

APJII [Asosiasi Penyedia Jasa Internet Indonesia]. (2019). Laporan Survei : Penetrasi \& Profil Perilaku Pengguna Interneet Indonesia. Buletin APJII, Edisi 40(Mei), 1-6. Retrieved from https://apjii.or.id/survei

Febrianti, C. (2017). Gaya hidup hedonisme mahasiswa Universitas Riau di Keluarahan Simpang Baru Kecamatan Tampan Kota Pekanbaru. JOM FISIP, 4(1), 1-15. https://doi.org/10.1017/CBO9781107415324.004

Hootsuite (we are social). (2019). Indonesia Digital Report 2019.

Ifwar, S. A. (2017). Lifestyle Visitor MP Club Pekanbaru. JOM FISIP, 4(1), 1-13.

Irawan, E. (2017). Instagram Sebagai Gaya Hidup Masyarakat Kota Pekanbaru. Jom Fisip, $4(2), 1-14$.

Juwita, E. P., Budimansyah, D., \& Nurbayani, S. (2015). Peran Media Sosial Terhadap Gaya Hidup Siswa. Sosietas, 5(1). https://doi.org/10.17509/sosietas.v5i1.1513

Khoirunnas. (2017). Pola Konsumtif Life Student City's Pekanbaru Province od Riau. JOM FISIP, 4(2).

Kotler, P., \& Amstrong, G. (2007). Principles of marketing (10th editi). New Jersey: Pearson Prentince Hall. 
Martini, E., Octavianty, U., \& Harsono, L. D. (2015). The Influence of Usage Intensity and Peer Group Interaction. In E-Proceeding of the International Conference on Social Science Research, ICSSR 2015 (Vol. 2015, pp. 405-412). Kuala Lumpur, Malaysia: ICSSR 2015.

Monks, F. ., Knoers, A. M. ., \& Haditono, S. . (2004). Psikologi Perkembangan; pengantar dalam berbagai bagiannya. Yogyakarta: Gadjah Mada University Press.

Mufidah, E. F., \& Wulansari, P. S. D. (2018). Gaya Hidup Hedonisme Mahasiswa Pascasarjana di Media Sosial. JKI (Jurnal Konseling Indonesia), 3(2), 33-36. https://doi.org/10.21067/jki.v3i2.2468

Praja, D. D., \& Damayantie, A. (2013). Potret Gaya Hidup Hedonisme Di Kalangan Mahasiswa (Studi pada Mahasiswa Sosiologi FISIP Universitas Lampung). Sociologie, 1(3).

Prasetyo, H. Y. (2019). Hubungan intensitas penggunaan Instagram dengan Prilaku Hedonisme pada mahasiswa bimbingan dan Konseling. Jurnal Riset Mahasiswa Bimbingan Dan Konseling, 5(9), 684-693.

Sakti, B. C., \& Yulianto, M. (2018). Penggunaan Media Sosial Instagram Dalam Pembentukan Identitas Diri Remaja. Interaksi-Online, 6(4), 1-12. Retrieved from https://ejournal3.undip.ac.id/index.php/interaksi-online/article/download/21950/20197

Syamsoedin, W. K., Bidjuni, H., \& Wowiling, F. (2015). Hubungan Durasi Penggunaan Media Sosial Dengan Kejadian Insomnia Pada Remaja Di Sma Negeri 9 Manado. Jurnal Keperawatan UNSRAT, 3(1).

Utari, M. (2017). Pengaruh media sosial Instagram Akun @ princessyahrini terhadap gaya hidup hedonis para followersnya. JOM FISIP, 4(2), 1-22. 